\title{
LA MÉTRICA EN LOS AUTOS SACRAMENTALES DE BANCES CANDAMO
}

El presente estudio de métrica se enfoca desde el punto de vista del uso y función ${ }^{1}$ que ésta tiene en los autos de Bances Candamo ${ }^{2}$ y además - siendo nuestro autor un escritor límite- ver cuál es la evolución que han sufrido, en este aspecto, las normas del Arte Nucvo ${ }^{3}$ de Lope hasta llegar a él. Lifectivamente, como demostrarcmos, existe un cambio y, sobre todo, una cousolidación de esas reglas; así, notaremos cóno la polimétrica tiene su razón de ser, una causa que justifica el uso de un metro u otro según la función que se le quiera dar a una determinada situación o personaje. Naturalmente, nos damos cuenta de lo problemático que es este planteamiento, y más tratándose de autos, no de comedias (más ricas en mutaciones). No obstante, opinamos que se puede ofrecer mayor interés y aportación de esta manera.

Por otra parte, y dada la condición de la época, la mentalidad y la coyuntura que vive Candamo ${ }^{4}$ nos ha inducido a buscar también innovaciones dieciochescas, que, por entonces, estaban en gestación.

Para todo ello procedenos de la siguiente manera: de cada auto damos,

1 Vid. Duago Marín. Uso y función de la versificación en Lope, Valencia ed. Castalia, I962.

2 Poesias completas, obras posthumas. Madrid. Blas de Villa-Nueva. A costa de Joseph Antonio Pimentel, I722, 2 vols. 20,5 cus. Tomo I: Auto Sacramental del primer duelo del mundo. (upues la naturaleza... pp. 6-35). Tomo II: Auto Sacramental Alegorico el gran chimico del mundo ("gran providencia mia.... pp. 7-4I). Auto Sacramental alegórico, las mesas de la fortunna. ("Escuchad el pregón de las mesas... pp. 438-507).

3 LOPE DE VEGA. Arte nuevo de hacer Comedias. B. A. E., vol. 38 .

- Vid. Francisco Banceis Candamo. Theatro de los Theatros de los passados y presentes siglos. Prólogo, edición y notas de Duncan W. Morr. London. Támesis Books Limited, I970. pp. 17-36. 
en primer lugar, una tabla de la versificación, donde se puede observar el metro, la rima, la cantidad de los versos, el acento y un resumen cuantitativo ${ }^{1 ;}$ después, hacemos dos apartados, A) y B). In el primero, estudiamos la valoración y caracterización estrófica, y en el segundo, un esquema clel uso y función que, a pesar de su complejidad, consideramos bastante significativo, pues nos muestra el tipo de estrofa, número de versos, los personajes y la función de aquélla. Seguidamente, estudiamos lo mismo en algunos autos de Calderón ${ }^{2}$, para que puedan compararse con los de Bances, explicando cuales son las diferencias entre uno y otro, lo cual nos facilita el cuadro resumen de los autos de Bances que va al final, $y$, por último, expondremos las conclusiones a que hemos llegado.

TABLA DE VERSIFICACION DEL AUTO SACRAMENTAL LAS MESAS DE LA FORTUNA

\section{Romances}

OCTOSfLABOS

Asonancia en 0

Asonancia en $e$

Asonancia en $e, 0$

Asonancia en $i$

Asonaucia en $a$

Asonancia cn $i, 0$
ACENTO

agudo: $9-282$

agudo: $42 \mathrm{I}-436,453-464$,

$484-496,508-5 I 5$

$517-530$

agudo: 1.003-1.022

grave: $540-979,983-994$

agudo: 1.061-r.013

grave: $1.508-1.902$

Romances con la misma rima que los anteriores

Romances en eco
Romances en estribillo
$80-95$

I-8, 506-507, 5I6 \& . 53I-532, 980-982. $995-\&{ }^{2}, 1.023-1.024 \cdot \& \mathrm{~s}, 1.061-1.087$. I.II $4-1.149$

Pareados: $283-362,419-420,437-452,465-481,482-483,496-497,498-505,533-$ 539, 997-1.002

Redondillas: I.025-I.060, I.104-I.I43, I.I50-I.507

Octavas reales: $363-418$.

1 Vid. ANronto QuñIs. Métrica Española. Madrid. Aula Magna. Id. Alcalá, I969, y Estrustura del encabalgamiento en la Métrica Española. Madrid C. S. I. C., I96.4.

2 Emilino Dfaz Iicharri. Teorias Metricas del Siglo de Oro. Madrid. C. S. I. C., 1970 . 
Número total de versos: 1.902

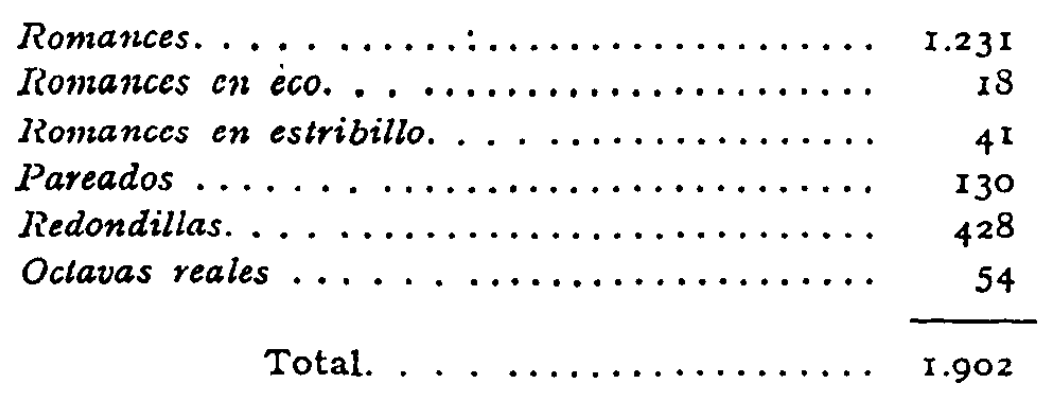

\section{A) VAIORACION Y CARACTERIZACION ESTRÓIICA EN EL AUTO LAS MESAS DE LA FORTUNA}

I.n cste auto Bances emplea cuatro tipos de estrofa perfectamente diferenciados. La que más abunda, por el número de sus versos, es el romance octosílabo, en seis tipos de rima (o, é, eo, i, a, io) (1ue componen en total $I .290$ versos (contando el estribillo y eco, que son romances por tener la misma rima), esto es, prácticamente las tres cuartas partes del auto. Con predominio del acento agudo sobre el grave.

El romance es una estrofa de raigambre popular que compartió con la redondilla el lugar preferente entre nuestros dramaturgos del Siglo de Oro. Navarro 'Tomás, en su Métrica española, considera que el romance ocupa en la obra dramática de Calderón el primer lugar, mientras que Lope y 'Tirso prefiricron la redondilla. Bances, cono demostraremos más adelante, en sus autos y en este aspecto se muestra seguidor de Calderón.

E1 análisis métrico de este auto no hace más que confirmar lo antedicho. Respecto al empleo del romance en esta obra, si lo relacionamos con el Arle nuevo de hacer comedias de Lope (aunque tal comparación no sea del todo justa, por no tratarse de una conedia), comprenderemos que no había una inflexible técnica dramática en relación con el verso, sino que cabían buen número de posibilidades eu la aplicación de los principios.

Dice Lope: "Las relaciones piden los romances". Y Bances los emplea sobre todo como nudo dramático y conversacional.

Es, pues, indudable que Bances se ha servido consciente o inconscientemente de un recurso estrúlico (el ronance octosílalo) para fijar un determinado momento en su obra: aquel que se refiere 
al aspecto polémico de la misma, sostenido en un ámbito dramático. Es decir, lo que podríamos llamar controversia dramática. Controversia, puesto que lo que se solventa es un problema ideológico; dramática, porque está enraizada en unas circunstancias de orden dramático, es decir, en un desenvolvimiento de la acción que es paralelo al polémico.

Iil cco lo incluimos en el Romance ya que en realidad es un 'romance en eco'.

La segunda estrofa en importancia numérica es la redondilla, forma que, como es sabido, fue muy empleada en todo el teatro clásico español. Cervantes ${ }^{1}$ definió el papel de las redondillas en el Viaje del Parnaso haciéndolas corresponder con la racamenta del barco, "que es siempre muy parleran. Lope señaló que las redondillas estaban bien para las cosas de amor. En Calderón son difíciles de encontrar y caracterizar. Bances las usa en este auto para dar muestras de arrepentimiento, amor y explicación a la propia conducta; diríamos que corresponde este metro al movimiento psíquico de la obra, como veremos al final cle estas explicaciones.

I a otra estrofa con mayor número de versos son los pareados. Pero tendremos que haccr una difcrenciación de tipos entre los pareados: del verso 203 al 362 suclen ir alternando, pero muy aisladamente, los endecasilabos con los heptasilabos, y en los restantes versos, suclen ser partes de canción o estribillo que se intercalan entre los roniances.

Según Navarro 'Tomás, los pareados endecasilabos AA:BB:CC:, servian en lemas y epitafios y en textos didácticos y morales. Aquí Bances los utiliza, en el primer tipo (versos 283-362), con carácter didáctico y moral.

En cuanto al estribillo (canción) formado por pareados, Navarro Tomás dice en la p. I53, apartado II7 de su libro Arte del Verso": "Se ha usado desde antiguo interrumpir el relato del romance para intercalar un estribillo que se repite a intervalos regulares».

Il estribillo suelen ser dos o más versos, octosílabos o de otra medida, con la asonancia del misno romance o con rima distinta. Es, como vemos, la misma definición que se podría dar del uso que hace, Bances en este auto con el estribillo (véase el esquema final).

$\mathrm{Y}$, por último, nos queda hablar de las octavas reales (versos 363-

1 Vid. Metrica Española, de T. NAVARRo. New. York Syracuse University Press, Syracuse, 1956.

- Tomis Navarro. Arte del verso. México. Colección ideas, letras y vida. Compañia General de Ediciones, S. A. 
4I8), de rima A-B-A-B-A-B-CC. En este metro hablan Noé, principalmente, Oráculo e Idolatría.

Aunque la octava real se utilizó por Boscán, Garcilaso, Montemayor, etcétera, eu poemas líricos y bucólicos, en esta época tenía ya un narcado siguificado, o mejor, uso épico. Lo podemos ver en Errcilla, Balbuena, Hojeda, etc. Eil teatro clásico se sirvió de la octava eu parlamentos graves y en escenas de ceremonia y dignidad. Bances la utiliza aquí con un marcado cariz épico, retador, altanero, amenazante. Véase esta octava:
A - Yo soy, mortales, el segundo Adan,
B - pues de mi buelve el Mundo a proceder,
A - cuantos oy vivos en sis esphera están,
B - a mi fecundidad deben el ser.
A - Aqui le enseñé a Italia el Vino y Pan
B - Conocer, cultivar, sembrar, coger:
C - Porque mi industria supo conseguir,
C - oro moler, granales exprimir. 


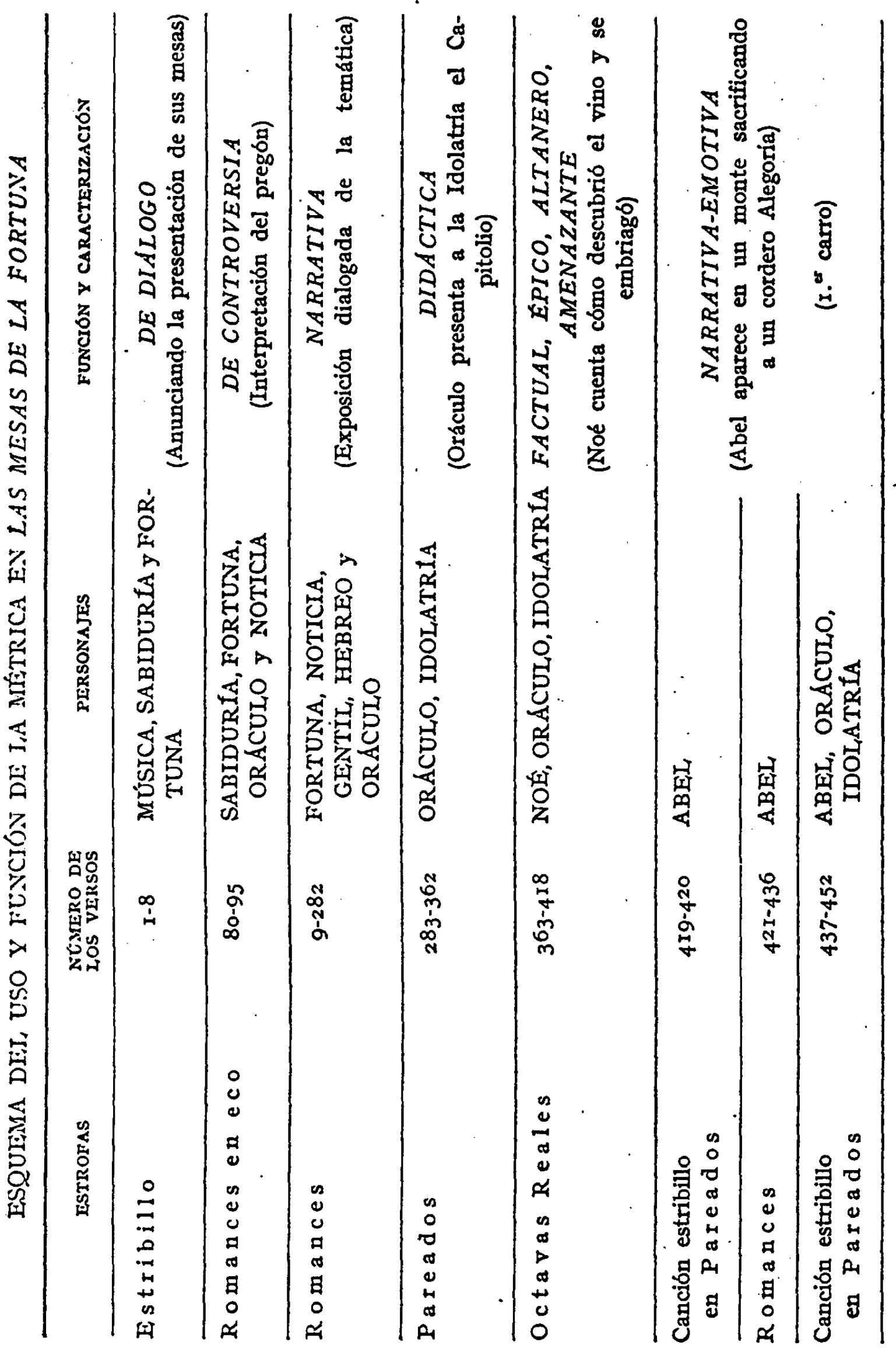


RFE, LVII, 1974-5

LA MÉTRICA EN LOS AUTOS SACRAMENTALES

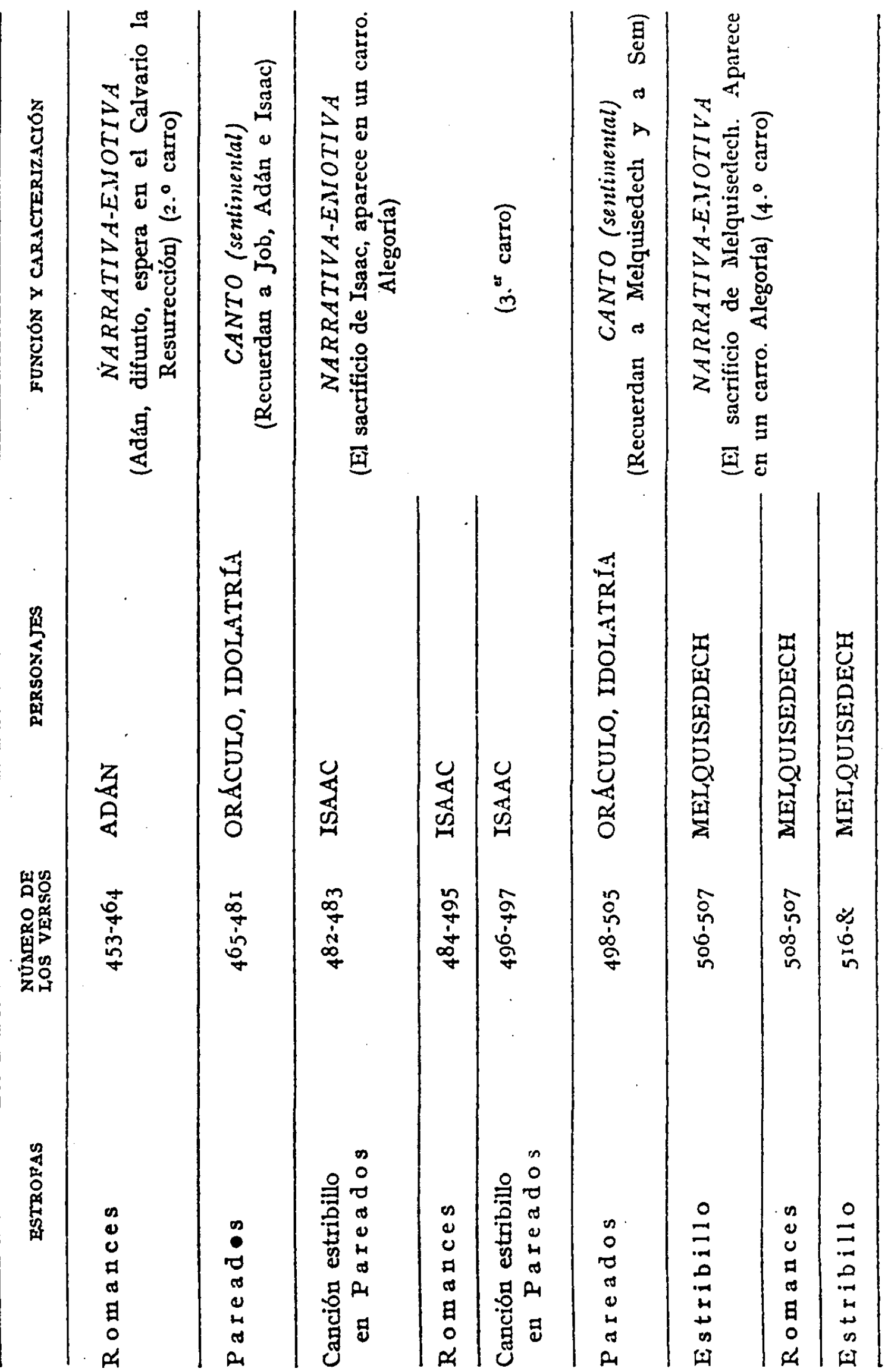

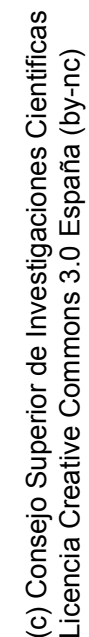


RFE, LVII, $1974-5$

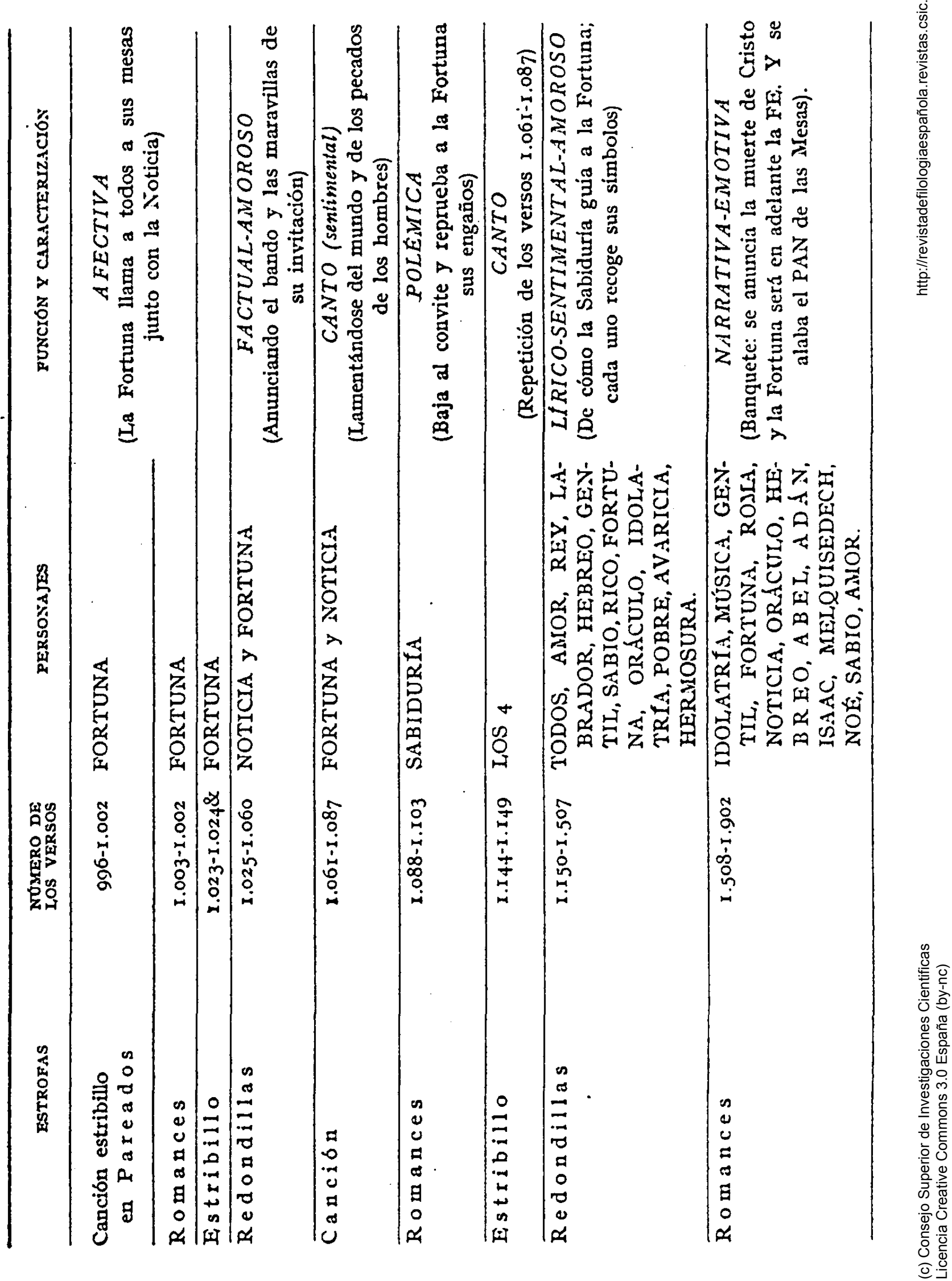


TABLA DE VERSIFICACION DEL AUTO SACRAMENTAL EL GRAN QUTMICO DEL MUNDO

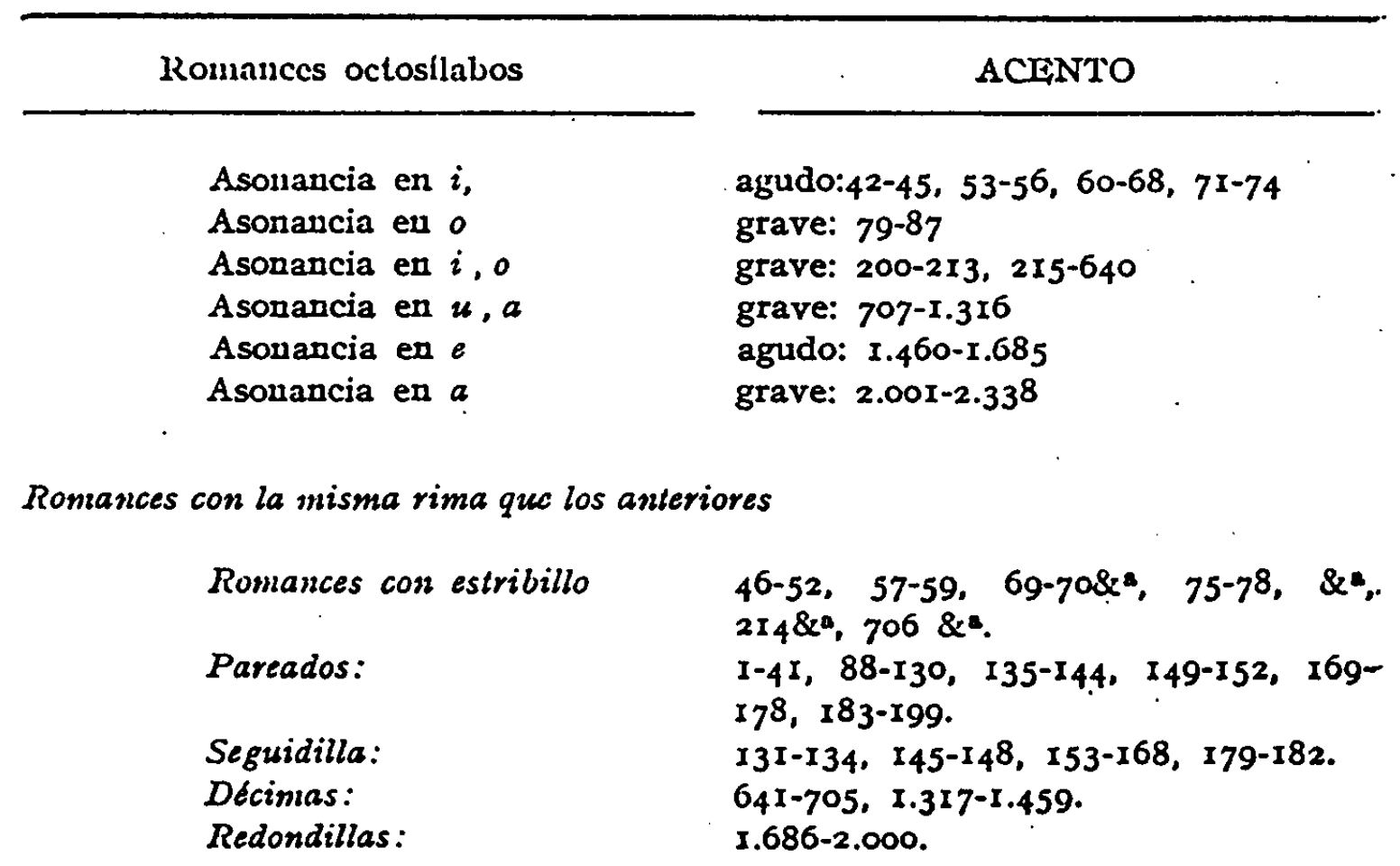

R E S U M E N

Número total de versos: $2.33^{8}$

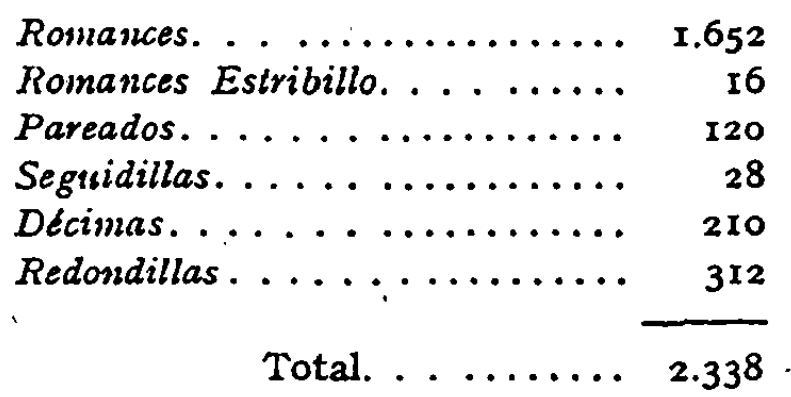

\section{VAIORACIÓN Y CARACTERIZACION ESTROFICA EN EL} AUTO SACRAMENTAL EL GRAN CHIMICO DEL MUNDO

Como podemos observar en el esquema, el autor emplea en este auto 5 tipos de estrofa; casi igual que en el auto anterior, en cuanto al número; pero hay dos nuevos tipos que son la seguidilla y la décima.

Lo mismo que en el anterior, el Romance ocupa el primer puesto; 
con un número total de versos de r.668 (contando el estribillo que, como en el anterior, sigue la rima del romance) que, sobre los 2.338 que tiene el auto, nos da una media de un 75 por roo, aproximadamente, de la totalidad de la obra. Tiene seis tipos de rima: $i, o$, io, ua, e, a, con predominio de acento grave (4 graves y 2 agudos). Bances los cmplea también como nulo dramático, conversacional, y en los grandes discursos monologados, como el del sabio en los versos 2 I 5 al 640 .

Las redondillas son también aquí las que siguen en orden de importancia numérica a los romances, y se han utilizado ell un total de 87 (3r2 versos). El uso que les da Bances es propiamente de tono amoroso, esperanzador, es ese pasaje donde todos esperan y desean la redención de sus pecados por la muerte de Cristo, el gran químico, que supo convertir mágicamente el pan y el vino en su Cuerpo y su Sangre. Luego, podríamos hablar del valor lírico de esta estrofa, ajustándonos a la opinión que Lope tenía, diciendo que «estaba bien para las cosas de amorn.

Los pareados ticnen siempre en este auto valor didáctico, y cuanda se trata de alabar y ensalzar a alguien, como puede verse en el esquema final, que, a nuestro juicio, es el que mejor deja apreciar estos valores $y$ diferencias entre las distintas estrofas.

El estribillo o canción es muy abundante en este auto y en el anterior pero, como ocurre en Las Mesas de la Fortuna, está sujeto casi siempre a la misma rima del romance, por lo que lo consideramos como parte de él. Lo mismo decimos del eco, para no insistir.

Las décimas son $2 I$, con un total de 2 IO versos, y están utilizadas en los versos 64I-705, donde hablan la Naturaleza, el Entendimiento, y los cinco sentidos corporales. Aquí se usa para hacerse entre ellos acusaciones y lamentacioues. Tiene un carácter triste y amargo.

En los versos I.317-I.459 hablan Entendimiento y Sabio. Ambos con un tono sentencioso y amenazador, es decir, también con ese carácter triste de los anteriores.

A Lope le parecieron buenas las décimas para las quejas. Lo mismo. se puede ver en el uso que les da Calderón generalmente. Véase cómo Bances va siguiendo esa misma línea.

Las seguidillas son en total siete ( 28 versos). Están usadas siempre para el canto (copla popular). Tiene un tono dulzón y pegajoso. Responden al esquema: $7,5,7,5$. 


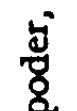

ชิ

5

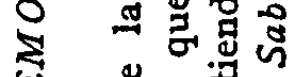

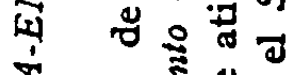

3

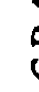

क्ष

龺

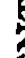

列

\&

吕

四

否

起 鵕

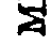

$\$$

동

总

.

螴

送

产

竞:

今 올

5 해웡

目彭表

₹ $3 \div$

으ㄱㅗㅗ

में \&

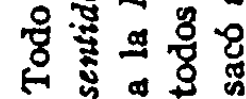

芑



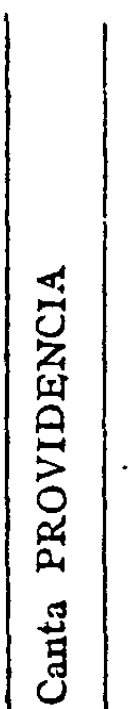

|

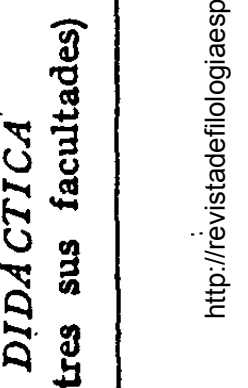




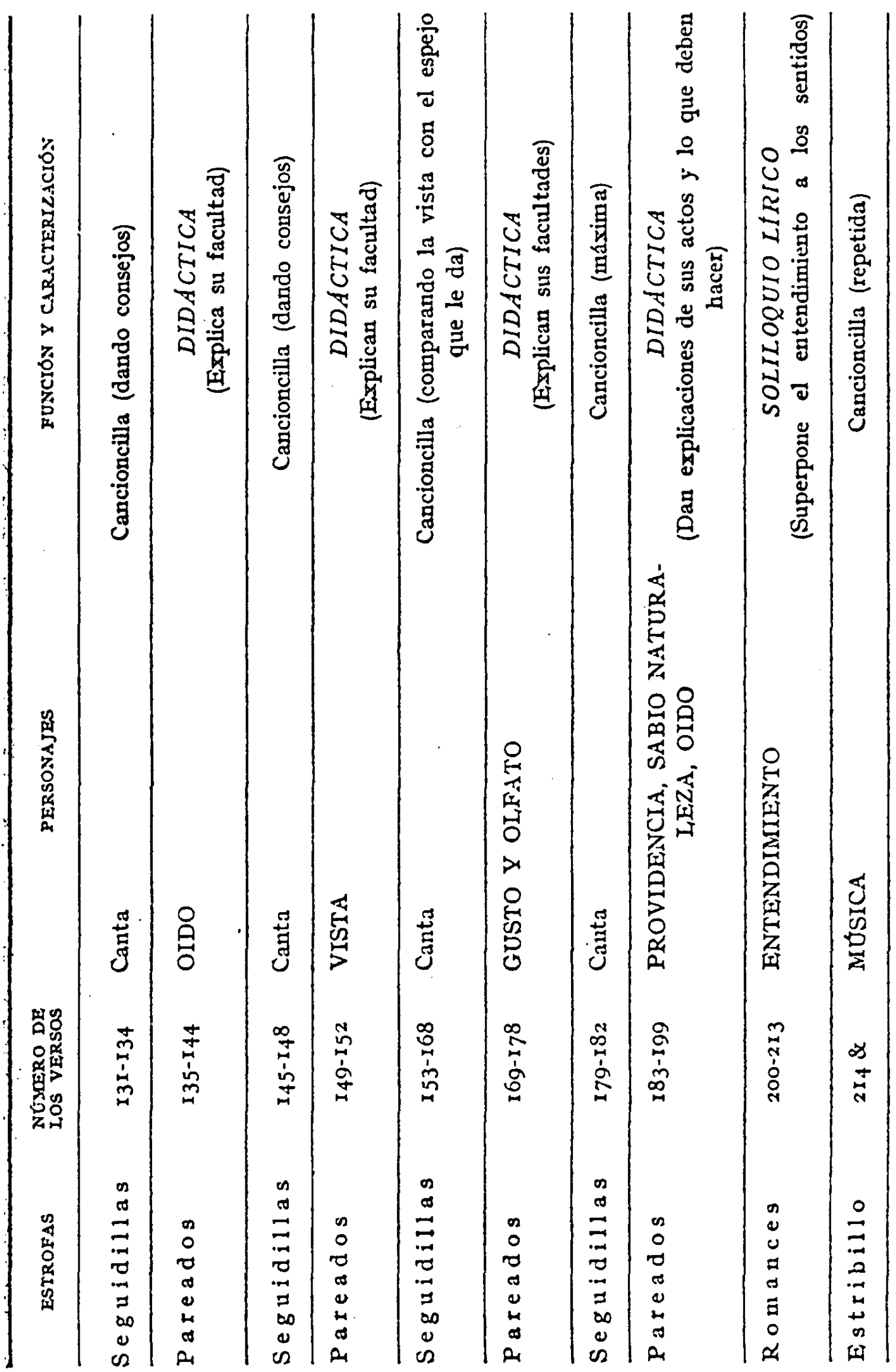


TABLA DE VERSIFICACIÓN DEL AUTO SACRAMENTAL EL PRIMER DUELO DEL MUNDO

Romauces octosilabos

Asonancia en $u, e$

Asonancia en $e$

Asonancia en $i$

Asonancia en 0

Asonancia en $e, a$

Asonancia en $e, 0$

Asonancia en $b$

Asonancia en $e$

Asonancia en 0

Asonancia en $a$

Asonancia en $a, e$
ACENTO

grave: I-596

grave: $568-726,735-760,766-832,839$.

873

agudo: $876-940,971-1.162$

agudo: 1.192-1.297

grave: $1.218-1.225$

grave: I.234-I.25I, I.4I2-I.4I5.

agudo: $1.273-1.37$ I, I.453-I.490

grave: $1.384-1.388$

grave: I.395-1.399

grave: 1.428-1.432

grave: 1.49 I-I. .798

Romances con la misma rima que los anteriores:

Estribillo: $731-734,761-765,833-838,874-875$.

Pareados: I.163-1.191, I.208-1.217, I.226-1.233, 1.252-1.263, I.382-1.383, I.393I.394, I.404-I.495, I.4IO-I.4II, I.4I I-I.42I, I.426-I.427, I.433-I.434.

Sueltos: (cridecasilabos y octosilabos): I.264-I.272, I.435-I.452.

Décimas: $941-970$.

Redondillas: 507-567, 727-730, I.372-I.38I, I.389-I.392, I.400-I.403, I.406-I.409, I.422-I.425.

Número total de versos: 1.798

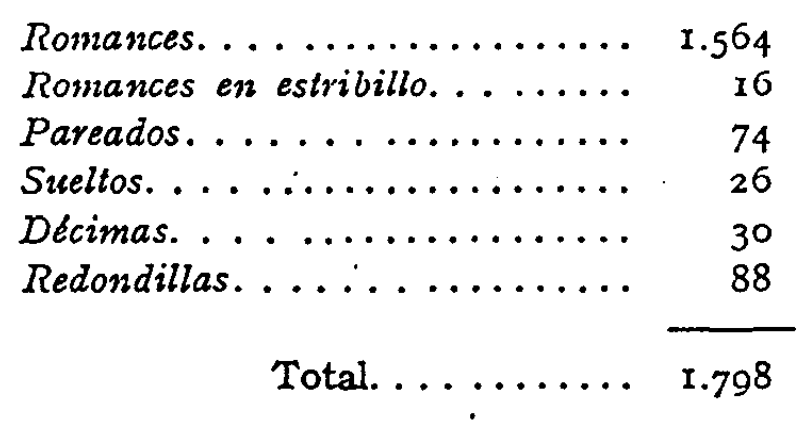


A) VALORACION Y CARACTERIZACIÓN ESTRÓFICA EN EL, AUTO SACRAMENTAL EL PRIMER DUELO DEL. MUNDO

También en este auto Bances emplea cuatro tipos de estrofa, aunque propiamente se puede hablar sólo de cuatro, destacando, como en los anteriores, el romance, con un total de $\mathrm{r} .58 \mathrm{o}$, versos con once clases de rima (ue, e, i, o, ea, eo, e, o, a, ae). El valor y el carácter de estos romances es igual también que en los anteriores: los emplea como nudo dramático, en los diálogos, controversias dramáticas, etc., en las descripciones y narraciones monologadas. Esto 10 podemos observar en los versos I.506-I..., y I.49I-I.798, principalmente (véase el esquema al principio de este apartado). Hemos decidido aqui, y con el objeto de ver otra característica de la métrica de los romances de Candamo, hacer un estudio de un trozo de romance para que se observen las cualidades de éstos; aunque el trozo pertenece al presente auto se puede aplicar lo dicho para los anteriores y siguientes:

Tenemos en estos autos el "poema poliestrófico disimétrico ${ }_{\|}$, donde la desigualdad cuantitativa de la unidad estrófica hace que resulte indeterminado el número de versos que se integran en la obra poética. La fragmentación simétrica del paradigma romancero es consecuencia de la finalidad expresiva del poeta.

Analizamos a continuación el siguiente fragmento del auto El Primer Duelo del Mundo (versos 7 al 20):

$$
\begin{aligned}
& \text { Donde nos esconderemos } \\
& \text { al ver que el cielo se anuble; } \\
& \text { Donde yre que denti muerte } \\
& \text { La Ymagen no meperturbel } \\
& \text { Ay ynfelice de mi } \\
& \text { adonde contigo huye } \\
& \text { deseo, mi planta? adonde } \\
& \text { temor la fuga me ynduces? } \\
& \text { Si contra mi conjurados } \\
& \text { los abimos se descubren } \\
& \text { Los cielos ya se desploman } \\
& \text { Los exes del orbe cruxen } \\
& \text { ay demil que de un Beneno } \\
& \text { el vocado aquete ynduje. }
\end{aligned}
$$

Análisis de los ritmos estróficos

Dón-de-nos-es-con-de-re-mos al-ber-que el-cie-lo-se a-nú-ble

$d \delta n$-de $y$-re-que-de-mi-muer-te

La $y$-ma-gen-no-me-per-túr-be

1 Vid. RAFAEI, DE BAIBIN. Sistema de ritmica castellana, Madrid. Gredos, I962. 
Presentan total isometría de base octosilábica. La inflexión o cumbre distensiva se localiza en la penúltima unidad métrica. Vemos, pues, como se da una total simetría en la localización de la cumbre tonal o melódica.

Enl la configuración acentual observemos asimismo, simetría del último acento iutensivo de cada grupo melódico (en la $7 \cdot^{a}$ sílaba) y desigualdad en la colocación de los restantes acentos.

El axis rítmico se podrfa entonces representar esquenáticamente:

dónde nos esconde - - ré- mos
al ber que el cielo se a - nú - - ble
dónde yré que de mi - - muér - - te
la Ymágen no mepe - - túr - - be

La unidad cuantitativa penúltima -en todos y cada uno de los grupos melódicos o versos- resulta así relevada y enriquecida, en comparación de las demás unidades de cada verso, con valores rítmicos fundamentales. Essta unidad penúltima reúne:

A) El máximo tonal, correspondiente a la inflexión melódica distensiva.

B) El máximo intensivo, vinculado normalmente al acento final.

C) El máximo de perceptibilidad, entre las articulaciones que riman, representado por la vocal acentuada.

D) La rciteración múltiple y periódica de estos máximos ritmicos a lo largo de la estrofa.

Se ha de tener en cuenta que en este auto y al hablar del romance, tenemos que hacer una observación: del verso 1.767 al I.770 (ambos inclusive) y del $\mathrm{r} .795$ al $\mathrm{x} .798$, hay dos cuartetos con la misma rima asonante, en $a e$ que la del romance, por lo que las hemos considerado parte integrante de éste.

En los autos de Bances podemos comprobar lo que nos dice Navarro Tomás en su Métrica Española sobre el romance en el Siglo de Oro. En ellos se excluye la rima consonante haciéndose definitivamente en rima asonante, y hay un marcado predominio del acento grave sobre el agudo. En este auto concretamente existen, sobre los once tipos de rima mencionados, ocho que son graves y cuatro que son de rima aguda, con un reducido número de versos.

En cuanto a los demás tipos de estrofas, hemos de añadir muy poco a lo ya mencionado de estos mismos tipos en los autos anteriores, y así tenemos las redondillas, que son 22 con un total de 88 versos y 
están utilizadas en aquellos trozos de mayor lirismo (amor, sentimiento, etcétera. Es de destacar el frecuente uso de una redondilla y, a continuación, un pareado o un estribillo, como se comprueba desde el verso I.372. También hemos visto cómo las redondillas constan de tres versos licptasílabos y un endecasílabo final con rima consonántica total respondiendo a la rima abrazada: a b b A.

Los pareados están utilizados en los pasajes donde se quiere explicar algo o aleccionar, y formando parte final de canciones, igual que en los autos anteriores.

$\mathrm{Y}$, por último, las décimas, que van desde el verso $94 \mathrm{I}$ al 970 , dichas por la Naturaleza y la Imaginación, tienen este tono de dolor, amargura, arrepentimiento, etc. triste en una palabra, que les atribuimos también a las décimas que aparecen en el auto El Gran Chimico del Mundo. 


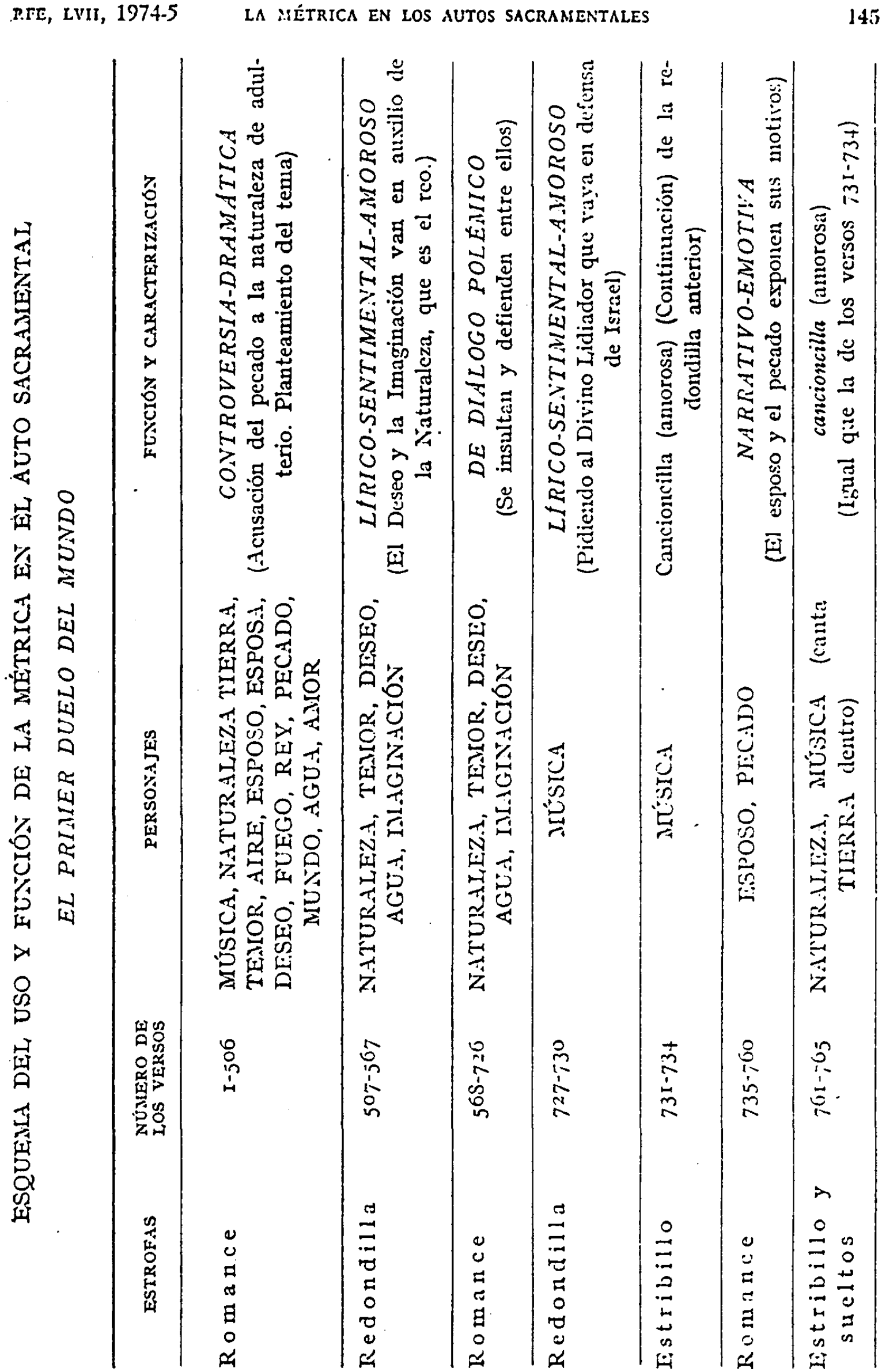




\begin{tabular}{|c|c|c|}
\hline ESTRORAS & $\begin{array}{l}\text { NCSIERO DE } \\
\text { LOS VERSOS }\end{array}$ & FUNCION Y CARACTERYZACION \\
\hline Rom a nce & 766.832 & $\begin{array}{l}\text { NATURALEZA, MAGINACION, } \\
\text { ABRAHAM, ESPOSO, PECADO, } \\
\text { DESEO }\end{array}$ \\
\hline $\begin{array}{l}\text { Estribillo y } \\
\text { sueltos }\end{array}$ & $833-838$ & $\begin{array}{c}\text { NATURALEZA, canta, AGUA, y } \\
\text { WÚSICA }\end{array}$ \\
\hline Romance & $839-873$ & 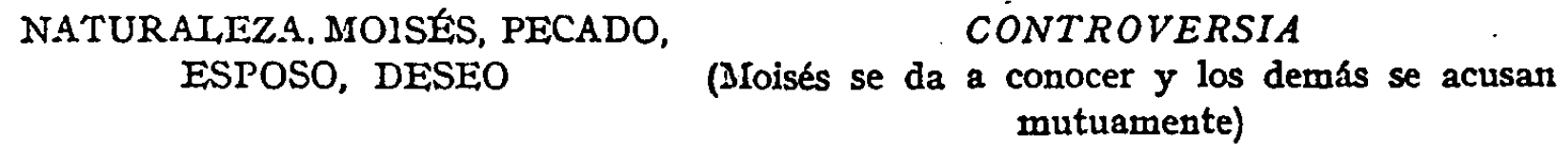 \\
\hline Estribillo & $874-875$ & Cancioncilla (igual a la anterior) \\
\hline Romance & $876-940$ & $\begin{array}{cc}\text { SANSON, PECADO, NATURALE } & \text { DIALOGO POLEMICO } \\
\text { ZA, ESPOSO, ELFAS, TEMIOR } & \text { (EI Pecado vence a todos incluso a Sansón) }\end{array}$ \\
\hline Décimas & $94 I-970$ & $\begin{array}{l}\text { ESPANTO, DOLOR, ARREPENTIMIENTO } \\
\text { (Queja de Naturaleza por haber pecado) }\end{array}$ \\
\hline Rom a nce & $971-1.162$ & $\begin{array}{l}\text { POLEMICA } \\
\text { (Los dos se dan explicaciones sobre su postura } \\
\text { y sus ideas) }\end{array}$ \\
\hline P a rea dos & I.163-I.I91 & $\begin{array}{cc}\text { IMAGINACION, canta, AYRE, NA- } & \text { DIDACTICO-MORAL } \\
\text { TURALEZA, } & \text { (Imaginación aconseja a Naturaleza, la Medicina } \\
& \text { y el por qué de ésta) }\end{array}$ \\
\hline
\end{tabular}




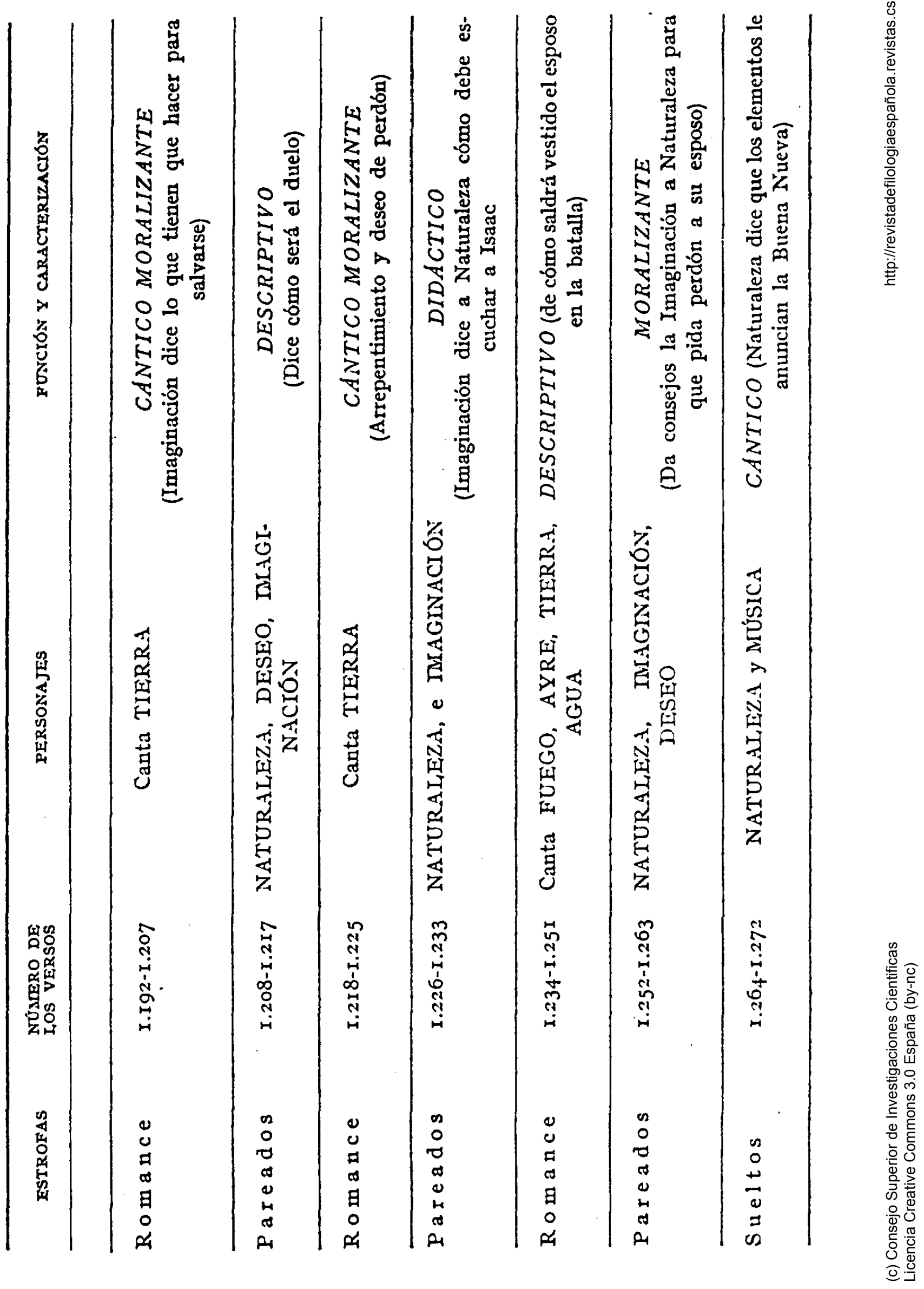




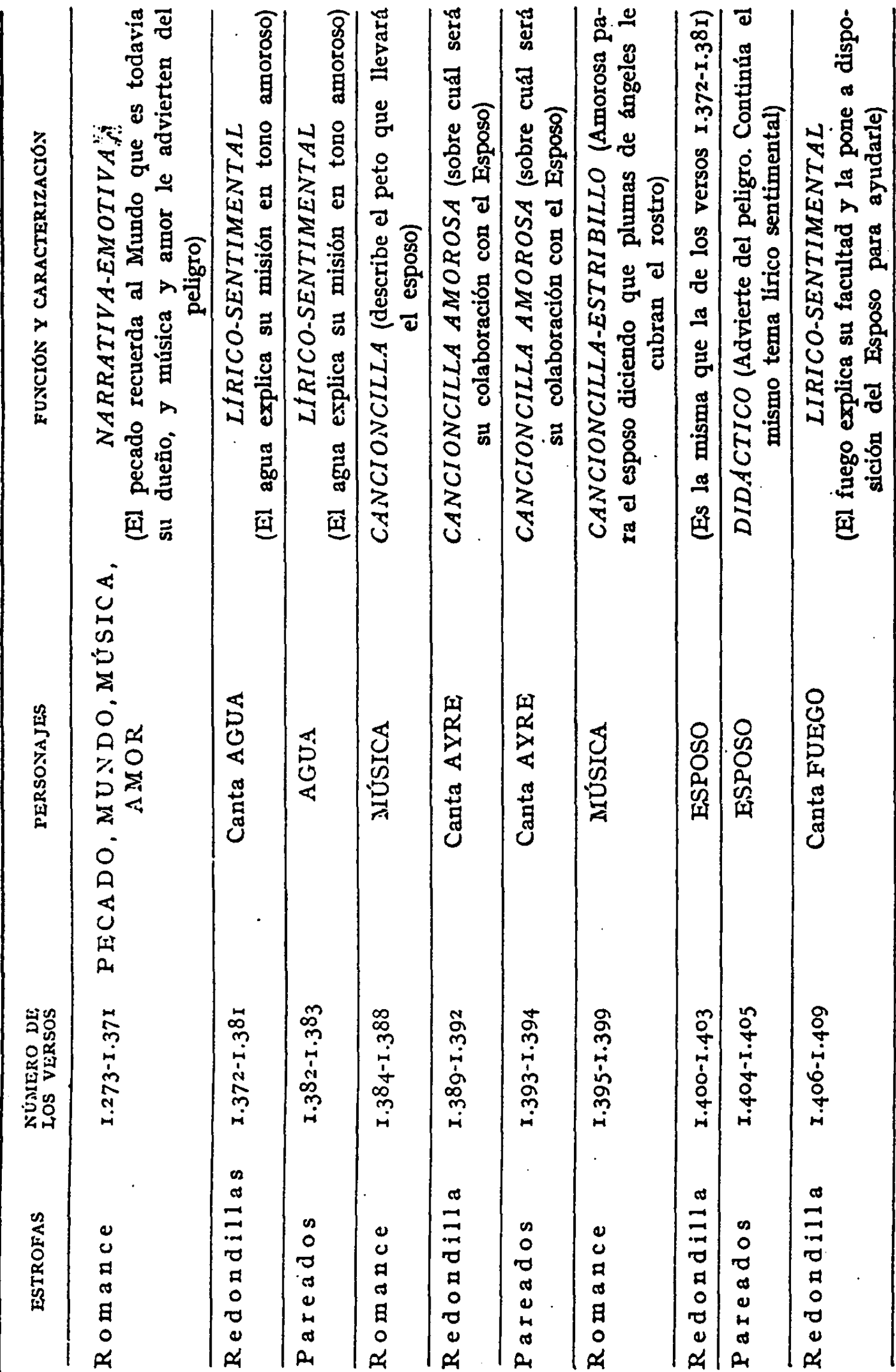

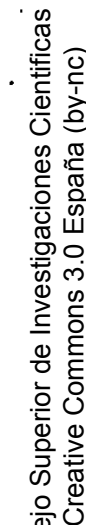




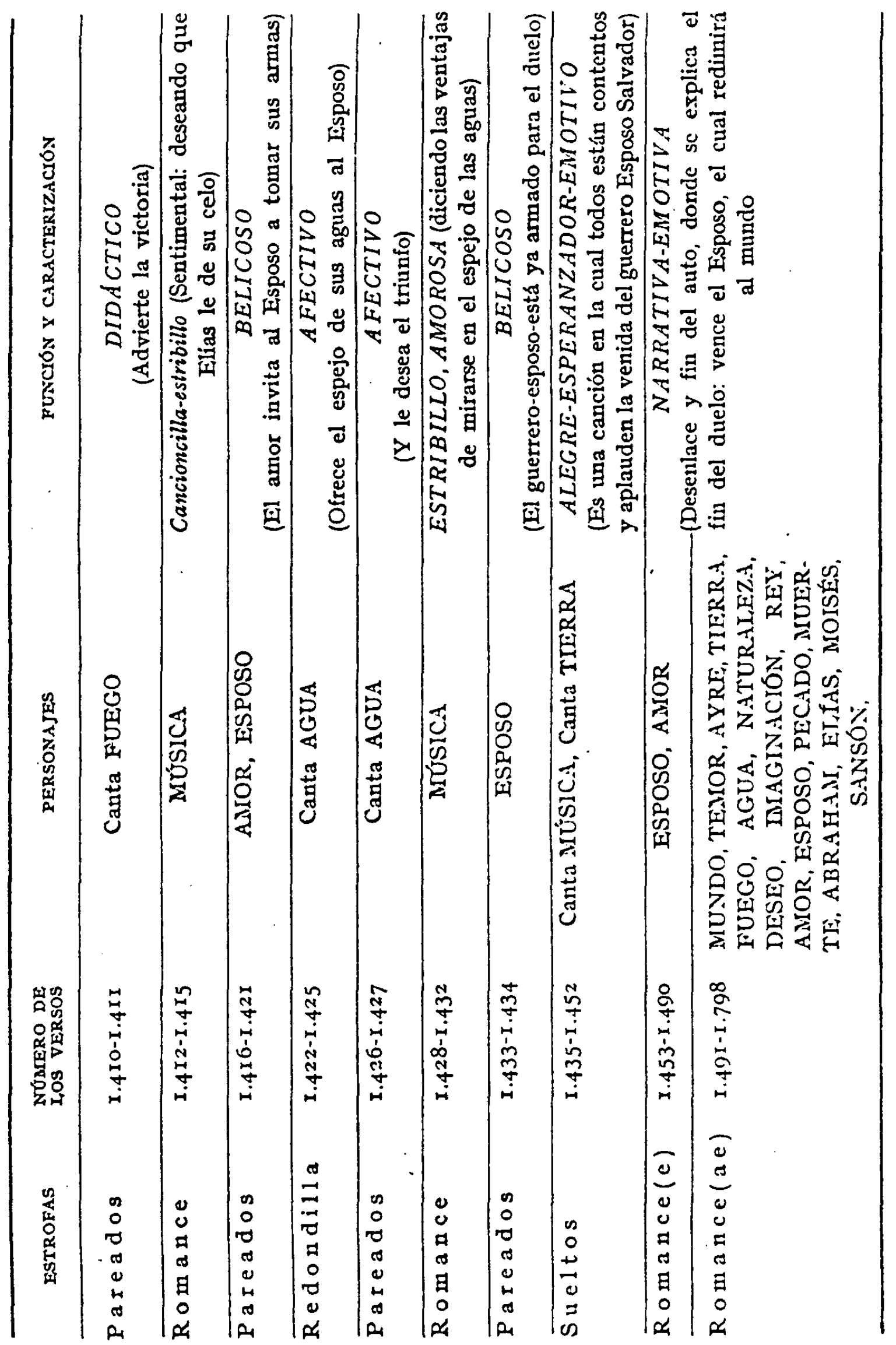


COMIPARACIÓN DE LA MÉTRICA DE BANCES CON LA MÉTRICA DE ALGUNOS AUTOS DE CALDERON

Iistudiamos la métrica y su uso en varios autos de Calderón a fin de poder comparar este estudio con el de Bances, ya que Calderón, como veremos a lo largo de todo este trabajo, tiene una gran influencia sobre nuestro autor en casi todos los aspectos.

Los autos de Calderón donde hemos hecho el estudio métrico son: Los alimentos del Hombre, Llamados y escogidos, El árbol del mejor fruto, El cubo de la Almudena y La piel de Gedeón ${ }^{1}$. Creemos que con este trabajo podremos demostrar ampliamente lo dicho arriba.

El auto sacramental de Calderón Los alimentos del Hombre nos of rece las siguientes características:

\section{TABLA DLE VERSIFICACION}

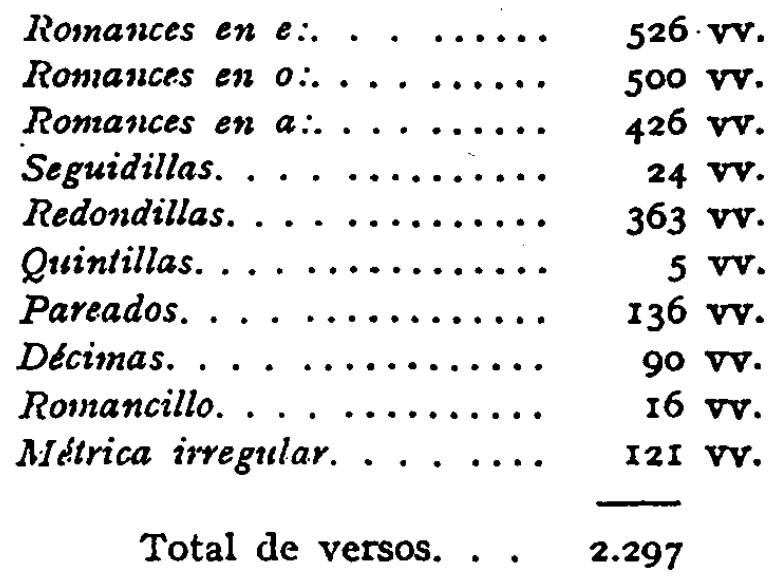

\section{VALORACION Y CARACTERIZACIÓN ESTRÓFICA}

Hay seis tipos de estrofas, de las cuales la más abundante es el Romance octosilabo ( $\mathrm{r} .452 \mathrm{vv}$.) con más de la mitad del total de versos.

El empleo insistente del romance sirve para fijar el aspecto polémico sostenido en un ambiente dramático.

El romance en $e$ aparece en la introducción. El de rima en $o$ en el desarrollo; y el romance en $a$ en la conclusión o desenlace.

1 Hemos utilizado: PFERO CALDERON de la BARCA Autos Sacramentales. nluras complefas, T. III. Recopilación, Prólogo y motas por ANGer Valiburina l'RAT. Madrid, Aguilar, 1959. 
La redondilla (rima consonántica: $8 \mathrm{a}-8 \mathrm{~b}-8 \mathrm{~b}-8 \mathrm{a}$ ) la utiliza Calderón para las quejas del personaje Adamo y en el momento en que pide a los cuatro Tiempos que le socorran.

Los pareados los utiliza para las escenas en que aparece el Demonio y habla con la Justicia; tienen carácter solemne.

Las décimas (Rima: 8a-8b-8b-8a-Sa-8c-8d-Sd-8c) las usa en la escena XVII, cuando Adamo se queja porque, después de pedir a los Cuatro Tiempos que le socorran, éstos solamente le dan instrumentos de trabajo; Adamo se lamenta, pues, como nunca ha trabajado, no sabe qué hacer, con los instrumentos que le han dado. Como se ve, Calderón da aquí a las décimas el mismo uso preconizado por Lope de Vega.

Las seguidillas (rima: $7 a-5 b-7 a-5 b$ ) las emplea en boca de personajes que tienen el mismo matiz expresivo de los estribillos, y que son repetidos varias veces por distintos personajes.

Los restantes metros (romancillo y quintilla) no aparecen en los. autos de Bances. Ambos han sido sustituidos ya por el romance.

\section{TABLA DE VERSIFICACION DEL AUTO SACRAMENTAL LLAMADOS $Y$ ESCOGIDOS}

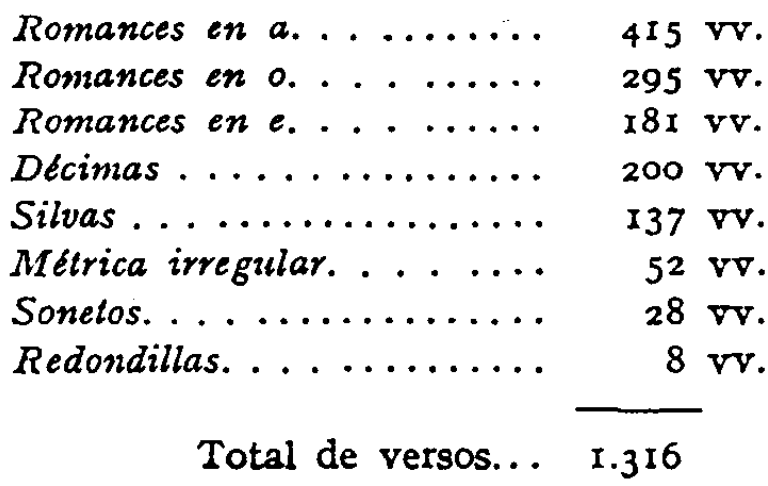

\section{VALORACIÓN Y CARACTERIZACIÓN ESTRÓFICA}

Utiliza cinco tipos de estrofas, de las que la más abundante es aquí también el romance octosílabo (8gI versos).

El romance en $e$ aparece en la introducción. En el desarrollo el romance en $o$ y el romance en $a$ en la conclusión o desenlace. Tiene también, como en el caso anterior, carácter polémico o de controversia dramática.

Las décimas las emplea para discutir un problema teológico (didáctico, pretende aleccionar al público): las dos naturalezas, la Humana y la Divina, discuten la Verdad y la Mentira. 
Las redondillas, de las que sólo hay dos casi al principio del auto (vv. I9-26), son cantadas, y en ellas se pide al Rey (Dios) que dé a su Hijo. Es como una súplica angustiada de todos los hombres que desean su salvación.

La métrica irregular se suele usar en la música. Ni silvas ni sonetos aparecen en los autos de Bances.

TABLA DE VERSIFICACION DEL AUTO SACRAMENTAL EL ARBOL DEL MEJOR FRUTO

Las características métricas de este auto son muy semejantes a las de los anteriores, como puede verse en esta sintesis que damos a coutinuación:

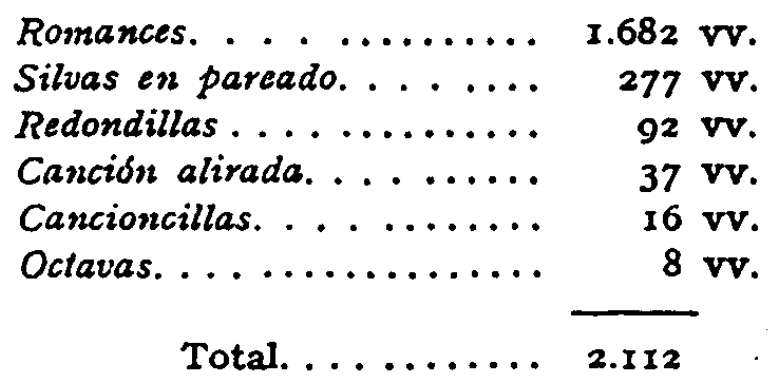

\section{VAIORACIÓN Y CARACTERIZACIÓN ESTROFICA}

Hay en este auto cuatro tipos de estrofas. Los romances ocupan el 85 por roo del número total de versos. Estos tienen carácter narrativo, - entremezclados de canciones que le dan matiz lírico.

La silva produce brevedad y precisión en los diálogos; tiene un touo imperativo y dinámico.

Las redondillas tienen un carácter estético, de ritmo muy apropiado para la narración.

La canción alirada se usa para hacer un elogio poético.

Las cancioncillas están llenas de lirismo, y las octavas tienen carácter musical.

En resumen, podemos decir que este auto es de carácter narrativolírico-musical, con poca acción y dinamismo.

\section{AUTO SACRAMENTAL EL CUBO DE LA ALMUDENA}

Los romances ocupan la casi totalidad del auto con un número de versos de $I . I 68$ con rima io al principio y eo al final. Las décimas, quintillas $\mathrm{y}$ redondillas ocupan el resto. 
La parte central tiene una distribución casi matemática entre redondillas y quintillas que están separadas por un cortísimo estribillo, cantado.

El romance del comienzo es descriptivo, bien del momento (toda 1a historia de las cuatro partes del mundo, doctrina y muerte de Cristo), bien de acción, lenta y sin violencia.

Calderón utiliza aquí el romance en discusiones filosóficas, chistes grotescos (con los que Alcuzcuz se dirige al público), y en la apoteosis final en que la Iglesia, triunfante, ve alejarse llenos de rabia a todos sus enemigos.

Las décimas las emplea a modo de silogismo; en ellas están escritos los versos en que comienza la iglesia a repartir oficios, momento que le sirve a Calderón para relacionar de una forma sutilisima a cada sentido corporal con una virtud teologal: El ofdo se va a encargar de la Fe, la vista de la Esperanza, el olfato de la Caridad; la penitencia y el ayuno son elevados a la categoría de las virtudes, y corresponden al tacto y al gusto, respectivamente. Las décimas están llenas de dinaunismo (como en la repartición del ejército de la Iglesia). También expresan la duda, en la clásica prueba del examen del pan por los sentidos y la Apostasía expone las razones por las que niega la presencia de Cristo en la Eucaristía.

Las redondillas las usa para los diálogos rápidos y cortos, lo misıno que hace con la quintilla.

TABLA DE VERSIFICACION DEL AUTO SACRAMENTAL LA PIEL $D E$ GEDE $O N$

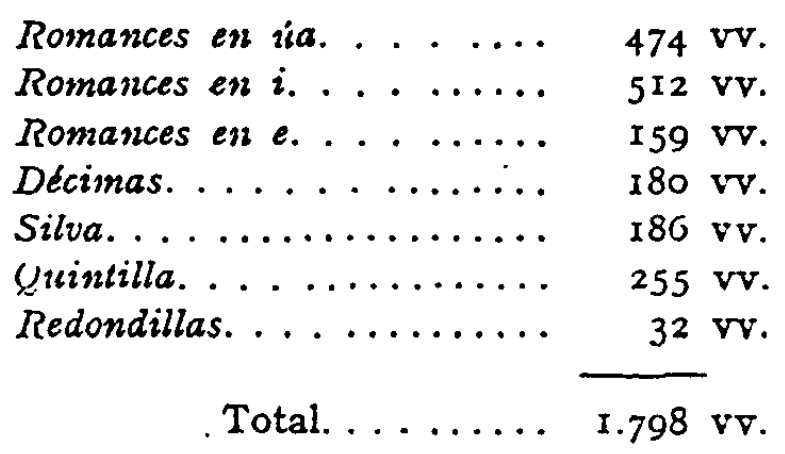

\section{VALORACIÓN Y CARAC'TERIZACIÓN}

Utiliza cuatro tipos de estrofa principales, siendo, como de costumbre, el romance el que ocupa el primer lugar en el número de versos, con I.II4, casi todos de rima aguda. 
La Idolatría es la que más los emplea, para describir sus estados de ánimo, sus narraciones y soliloquios.

I, a redondilla la utiliza en los parlamentos líricos o narrativos, y en los diálogos.

Ira silva ticne un carácter grave y lento, descriptivo y explicativo, donde la acción se detiene y remansa. Se limita a las alabanzas mútuas de Madián y Amalech.

Las décimas están usadas en el pasaje donde habla Idolatria, que se queja amargamente de su suerte $y$, al ofr gritos que piden que se derribe el f́dolo Baal; aumenta más su dolor.

En otra ocasión aparecen usadas alternativamente por Mies, Monte y Prado, que se quejan a la Aurora de que no esparza ésta en ellos el rocí, sino solamente en la piel de Gedeón.

Resumiendo, podemos decir que la controversia dramática viene expresada en romance, la parte lírica en redondillas, y la silva tiene un carácter estático y descriptivo.

Incluinos un esquema-resumen de la métrica en los autos de Bances para comprobar la gran semejanza de la métrica usada por Calderón, el maestro, y Bances, el discípulo.

FSQUEMA RESUMEN COMPARATIVO DE LA METRICA EN LOS AUTOS DE BANCES

IAS MESAS DE LA FORTUNA

Romances..........23I

Romances eco. ....... 8

Romances en estribillo.4 $\mathrm{I}$

Pareados. . . . . . . I30

Redoudillas. . . . . 428

Octavas reales.......54

TOTAI DE VERSOS. 1.902
IL GRAN CHFMICO DEL, MUNDO

Romances. . . . . . r.652

Romances en estribillo.I6

Pareados............20

Seguidillas. . . ....28

Décimas... ......210

Redoudillas. .....312

$2.33^{8}$
EL PRIMER DUELO DEL MUNDO

Romances. . . . .....564

Romances en estribillo. I6

Pareados.........74

Sueltos. . . ......26

Décimas. . . . . . . 30

Redondillas. . . . . .88

I.798

\section{CONCLUSIONES}

Con este estudio de los problemas métricos en Bances se pueden sacar algunas conclusiones bastante evidentes sobre. la evolución de 1a métrica, desde los preceptos del Arte muevo de hacer comedias hasta nuestro autor, que viene a ser como una proyección de Lope, Góngora y Calderón, sobre todo de éste últino. 
Puede deducirse, aproximadamente, lo que inclinaba a Bances a clegir y cambiar los distintos metros en relación con la situación dramática y particularmente la evolución de las preferencias métricas.

Bances es barroco en la métrica, ya que utiliza diferentes metros scgún la situación dramática, y en lo que respecta a la de sus autos no aparece ninguna innovación - diganos-dicciochesca, sino que los metros aparecen más evolucionados, lógicamente. Yor ejemplo, al comparar con Calderón, observamos que éste utiliza más la rina aguđa en los romances; Bances, por el contrario, usa más la grave. Calderón utiliza la quintilla, la cual ha desaparecido y'a en Bances habiendo sido sustituida por la redondilla. Es de tener muy en cuenta la cantidad de versos cantados que hay eu los autos de Bances, pues su número y proporción supera a los de Calderón; con Bances la escena va a llegar a la cumbre, en donde se unirán todas las artes, y la música teudrá un papel muy importante. ${ }^{2}$

In cuanto al uso y función de las estrofas haremos dos apartados:

a) Metros castelianos: Romances, redondillas y décimas

b) Metros italtanos: octavas y canción

Los metros castellanos ofrecen mayor variedad de uso que los italianos; tanto en los monólogos como en los diálogos predominan los de carácter factual, con o sin conflicto dramático, sin distinción en cuanto al tono grave o ligero de la escena, ni al carácter elevado o humilde de los personajes.

Los preceptos de El Arte nutevo de hacer comedias nos dicen en los versos 305-312:
Acomode los versos con prudencia
a los sujetos de que va tratando.
Las dezimas son buenas para quejas
El soneto esiá bien en los que aguardan,
Las relaciones piden los romances, Aunque en octavas liszen por estremo. son los tercetos para cosas graves. $Y$ para las de amor, las redondillas.

Veamos cómo se da esto nismo en Bances en unos casos, y cuál es su evolución en otros.

1 Vid. JosE J. PRRtz Fridu. Autos Sacramentales de Francisco Bances Candamo, Ovicio. Instituto de Rstudios Asturianos del Patronato José Maria Quadrado (C. S. I. C.), 1975. 


\section{a) Metros castelianos}

Décimas: monólogos, soliloquios líricos, con tensión dramática. Cuando se utiliza para relaciones es significativo que éstas sean de carácter lírico descriptivo, en forma de interpelaciones retóricas y nunca sean relaciones factuales $y$ afectivas (como en los romances). Fin las quejas, dolor y arrepentimiento, es donde más suelen aparecer.

En I,ope la quintilla disminuye desde la segunda época, en Calderón. son muy escasas, $y$ en Bances ya no aparecen.

La redondilla disminuye en el uso ya desde las dos últimas épocas. de Lope y tienden a dedicarse en proporción creciente al diálogo -cosa que en Bances se cumple perfectamente- más que al monólogo. Cesa por completo en ciertos tipos de monólogos o diálogos como en las relaciones narrativo-emotivas para las que el romance queda como. tipo favorito. Bances las suele utilizar en pasajes de carácter líricoamoroso-sentimental.

El romance, que empieza dedicado exclusivamente a las relaciones, tiende a diversificar sus funciones a medida que aumenta su frecuencia, como lo podemos ver a partir de la segunda época de Lope y llega a Bances, que lo utiliza principalmente para los diálogos, a expensas. de las redondillas $y$ quintillas.

El tipo de diálogo para el que se utiliza el romance es el dinámico.

\section{b) Metros italianos:}

Octavas: Para diálogo factual especialmente con conflicto dramático, en tono elevado y situación grave. La sobriedad expresiva. carente de artificios retóricos es nota regular en tales diálogos.

La Canción se da principalmente en monólogos, tanto líricos como. factuales pero siempre en situaciones graves y con elevación de sentimientos.

Cambios métricos: Los cambios métricos, generalmente, sirven para. reforzar las mutaciones de escena (con su cambio usual de asunto, lugar o personaje) y cuando no ocurre así se puede deber al deseo deresaltar el enlace temático de escenas distintas mediante la continuidad. métrica.

En el paso de una subescena a otra (es decir, al entrar o salir algún: personaje) lo ordinario es conservar el mismo metro. Cuando se producen. cambios métricos al comienzo de las subescenas, suelen ir acompañados, 
de un cambio en la forma (diálogo o monólogo), o en la situación (asunto o personajes), o en el tono dramático.

Bances no basa el cambio métrico sólo en el cambio automático de subescenas, sino que atiende también al contenido y carácter de la situación.

Otra de las cosas que hemos observado en Bances es la repetición de algunos versos en diferentes autos, por ejemplo, en Las Mesas de la Fortuna el estribillo para llamar la atención es: "oild, atended, escuchad》, y en El Gran Quimico del Mundo, es: "Iisscuchad, atended, ofd》.

Como puede observarse, en Bances, a pesar de la polimetria, hay un destacado, casi único, uso del romance, más abundante en proporción que en Calderón y con matices más variados.

\section{JOSÉ PŔREZ FEITU}

\section{BIBLIOGRATIA}

\section{AU'TOS DE BANCESS CANDAMO}

A) Maunscritos:

(El Gran Chinico del Mundo-Las Mesas de la Fortunna-El primer Duelo del Mundo-La mistica monarchla).

(Fil un volumen de Autos Sacramentales, alegóricos e historiales de Diferentes Ingenios de esta Corte).

$3.4^{6}$ bs.; $4^{\circ}$ y 2 de portada $\mathrm{c}$ indice. Iretra del s. xviu, pery. ${ }^{\circ}$ D).

MADIRID, Nacional. (Ms. I4.840).

El Gran Chinico del Mundo:

(Auto Sacramcntal. Letra del s. xvmi $3^{8}$ hs., $44^{\circ}$ holandesa).

"Gran providencia mia"...

MADIRID, Nacional. (MIs. I4.099).

El Gran Chimico del Minndo.

Auto Sacrancntal Alegórico. De Iira. ${ }^{\circ}$ Candamo.

Letra del s. Xviu. 38 fols. $210 \times 150 \mathrm{~mm}$. Hol. ${ }^{2}$

MLADRID, Nacional (Ms. I6.804).

Las Mesas de la Fortunia.

- Auto Sacramental.

Letra de fines del s. Xvur. 29 hs. $4 .^{\circ}$ holandesa.

"Escuchad el pregón de las mesas...".

MADRID, Nacional. (MS. I5.5 19 ).

I.etra del s. Xvir. 27 hs. $4 .^{\circ}$ hol.a

MADRID, Nacional. (Mis. 14.819 ).

Letra del si xvir. 27 hs. $4^{\circ}$ hol. ${ }^{2}$

MADIRID, Nacional. (MS. I5.201).

Letra del s. Xvirr. 26 hs. $4 .^{\circ} 346$ hol., y 2 de portada e indice. Perg. ${ }^{\circ}$ (D). MADRID, Nacional. (Ms. $\mathrm{r}_{4} \cdot 8_{4}$ ). 
MADRID, Nacional. (Ms. I6.804).

(Este ms. 16.804 no pertenece al auto sacramental Las Mesas do la Fortuna, sino al auto El Gran Chimico del Mundo. También viene mál indicado en el catálogo de Paz y Meliá).

El primer duelo del inundo.

Auto Sacramcnial. I,etra del s. Xvm. 26 hs. $40^{\circ}$ hol.* (O.).

"Pues la naturaleza hoy nos destruye..."

MADRID, Nacional. (Ms. 16.409).

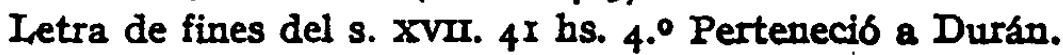

MADRID, Nacional. (Ms. 16.35I).

Letra del s. XVIr. 18 hs. 346 hs. y 2 de portada e indice. Perg. ${ }^{\circ}$ (D).

MADRID, Nacional. (Ms. 14.840).

\section{B) EDICIONES}

I.ONDRFS. British Museum, 87, b, r5/16.

MADRID, Academia Española. 4I-V-3I/32.

MADRID, Nacional. T-9.809/10.

PARIS, Nationale. $\mathrm{Yg} I 7 \mathrm{r} / 72$.

SANTANDLiR, "Menéndez I'elayo", R-V-8-25 (el II).

Las mesas de la Fortana (de Prancisco Bances Candamo) ("Iiscuchad cl pregón de las mesas... pp. 564-580).

In $A$ utos Sacramentales desde su origen hasta fines del siglo XVII. Colección escogida; dispuesta y ordenada por EDUARDO GONZSI,EZ PRDROso, Madrid, Rivadeneyra, I865. Págs. LXI + I h. + I h. + 590 pp. 25 cms. (Biblioteca de Autores Españoles, LVIII).

Las Mesas de la Fortinza (de Francrsco Bances Candano).

En Piezas maestras del teatro teolbgico español.... Selección, Introducción y notas de NICOIAS GonZÁLEZ RuIz. Madrid. (La Iedit. Católica. Imp. Sáez) 1946. 2 vols. 20 cms. // Tomo I, p. 889 //. Biblioteca de Autores Cristianos.

\section{OBRAS CONSULTADAS}

Alonso, Dámaso. La Lengita poetica de Gongora. Madrid. C. S. I. C. Anejo XX, R. F. E. 3." edición, I961. Temas gongorinos. I. La simetria en el endecasilabo de Gougora». R. F. E., 1927, XIV, pp. 329-346.

Versos plurimembres y poemas correlativos. R. B. A. M., 1944. núm. 49, pp. 89-rgr.

Versos correlativos y retórica tradicional. R. F. E., I944. XXVIII, pp. I39-I53.

Difago, Gerardo. Una estrofa de Lope. Discurso de ingreso en la R. A. E., Santander, 1948 .

LOPE DE VEGA. Discurso sobre la nueva poesta, incluido en la Circe, r624.

La Dorotea. Madrid, I913. 